\title{
iTRAQ-based proteomic analysis of the reproductive cycle characteristics of Hainan Black Goat, the unique species in China, Hainan Province
}

\author{
Haiwen Zhang ${ }^{1,2}$, Rui Hua ${ }^{1,2}$, Qingfeng Guan ${ }^{1,2}$, Kebang Wu $\mathbf{W}^{1,2 *}$ \\ ${ }^{1}$ Key Laboratory of Tropical Animal Breeding and Epidemic Disease Research of Hainan Province, Hainan University, Haikou, Hainan, 570228, \\ China, ${ }^{2}$ Laboratory of Tropical Animal Breeding, Reproduction and Nutrition, Hainan University, Haikou, Hainan, 570228, China
}

\section{A B S T R A C T}

\begin{abstract}
Hainan black goats are unique species in China, Hainan province, they are specific mutton goat breed and the tasty meat make the black goat to be one of the four famous dishes in Hainan. However, little knowledge was known about the reproductive cycle of this breed. So, in the study, serum samples of the reproductive period were collected, and high-throughput sequencing were conducted by iTRAO technology. The results showed the amounts of significantly different proteins between continuous period and the corresponding Go and COG annotation, KEGG enrichment of differential expressed proteins between each two periods were also analyzed. Further, continuously differential expression proteins of the whole cycle and differential expression proteins directly related to reproduction between two adjacent periods were also collected and annotated. This is the first study systematically uncovered reproductive cycle characteristics of Hainan black goats, the study preliminarily uncovered the basical protein information between each reproductive period, and the data could contribute to the built of highly efficient reproduction system of Hainan black goats.
\end{abstract}

Keywords: Black goat; Reproduction; Proteomics; iTRAQ; Protein

\section{INTRODUCTION}

Hainan black goats are unique species in China, Hainan province. With the climatic feature of hot and humid, the distinct dry rainy season, the black goats have been cultivated as resistance of crude feed, strong disease resistance, early sexual maturity and tender meat quality through natural selection (Wang et al., 2017). For the numerous excellent trait and considerable economic value, nowdays, industrialized farming of east goats has become a trend, and the chief problem was the relatively low reproduction rate and low milk production efficiency (Adamala, 2018; Al-zaqri et al., 2017; Kannan et al., 2018; Maddi et al., 2018; Troujeni et al., 2018).

iTRAQ (isobaric tags for relative and absolute quantitation) is the quantitative proteomic technology based on isotope labelling in vitro, which could analyses the differentially expressed protein and the related signal transduction pathway between different period (Howlader et al., 2018;
Hasan et al., 2018; Khan, 2018), it is one of the most popular proteomic technology nowadays (Moulder et al., 2017). iTRAQ-based proteomic analysis have been widely applied in the process of livestock production, comparative proteomic analyses of fiber diversity between sheep and goats provided a list of candidate proteins that involved in fiber formation ( $\mathrm{Li}$ et al., 2018), iTRAQ based technology was also applied to analysis the influence of overgrazing induced alterations in hepatic proteins of sheep (Ren et al., 2016). As in porcine production, iTRAQ-based technology has been used to analysis the in vivo muscle development distinctions during early embryonic development of different pig breeds (Zhang et al., 2016). To investigate the effect of transportation under high temperature conditions, iTRAQ technology was also applied to determine the changes in protein profile of pale, soft and exudative (PSE) - like muscles of broilers (Xing et al., 2017), which provided a further understanding of the mechanism of meat quality changes in response to stress, the technology also surveyed as a feasibility and sensitivity tool to reveal

\footnotetext{
*Corresponding author:

Kebang Wu, Key Laboratory of Tropical Animal Breeding and Epidemic Disease Research of Hainan Province, Hainan University, Haikou, Hainan, 570228, China. E-mail: 84413414@qq.com
} 
the molecular mechanisms underlying brown eggshell pigmentation (Li et al., 2016).

Serum proteomic analysis based on iTRAQ technique has been widely applied, for serum samples are easy to be acquired and biomarker candidates can be screened out more efficiently (Koutroukides et al., 2013, Tonack et al., 2009), i.e. iTRAQ based screen of serum of essential hypertension patients found certain special proteins and the interaction between them, which could better predict the occurrence and illustrate the pathophysiological mechanism of essential hypertension disease (Xu et al., 2017), potential serum biomarkers in locoweed-poisoned rabbits were also efficiently found based on iTRAQ test, which in turn could efficiently diagnosis the disease of locoism and provides a new insight of the pathogenesis of locoism (Jiao et al., 2017). The two-dimensional method was also used to evaluate specific characteristics in serum proteins of sheep with mild broncho-pulmonary disease, but compared with the iTRAQ technology (Yun et al., 2017; Chen et al., 2017), the traditional two-dimensional method was obviously less high throughput and with lower accuracy (Chiaradia et al., 2012).

As far as we know, there are no system-wide report about the whole reproductive cycle of goats so far (Basak and Gajbhiye, 2018; Basu et al., 2018; Garcia Alegria et al., 2017; Gonzalez-Trinidad et al., 2017; Kylili et al., 2018; Tu et al., 2018). To reveal the characteristics of the changing rule during the reproductive cycle of Hainan black goats, in this study, we used iTRAQ-based technology to reveal the potential serum proteomic information of black goats during continuously reproductive cycle(empty pregnant period, oestrum period, gestation period, lactation period), and certain functional proteins will be described, this is the first report on the changing rule of serum proteins of black goats during the reproductive cycle (Camara et al., 2018; Duan et al., 2018; Fu and Liu, 2017; Zong et al., 2018).

\section{MATERIALS AND METHODS}

\section{Serum collection of different reproduction period}

The blood samples $(6 \mathrm{~mL})$ were collected from 12 east goats (empty pregnant period, oestrum period, gestation period, lactation period, each period collected 3 individual blood samples as biological repeat), serum was collected from blood samples following the manufacture's protocol. Briefly, blood sample was incubated at room temperature for $2 \mathrm{~h}$ and centrifuged for $10 \mathrm{~min}$ at $3000 \mathrm{rpm}$ at $4{ }^{\circ} \mathrm{C}$, and the supernatant was transferred into a clean polypropylene tube and stored at $-80{ }^{\circ} \mathrm{C}$ for further use.

\section{Wipe off high-abundant protein}

Add $610 \mu \mathrm{l}$ rehydration reagent to the bottle of elution reagent to prepare rehydrated elution reagent. Get the serum protein $(\geq 10 \mathrm{mg})$, centrifuged at $10000 \mathrm{~g}$ for $10 \mathrm{~min}$, put off the bottom cap of spin column, transfer spin column to the centrifuge tube without cover, centrifuge 30-60 s at $1000 \mathrm{~g}$, get rid of stock solution and mount the bottom cap of spin column, open the top cap of spin column, add $200 \mu \mathrm{l}$ wash buffer, incubated at $26{ }^{\circ} \mathrm{C}$ for $5 \mathrm{~min}$, then open then bottom cap and transfer spin column to the centrifuge tube without cap, centrifuge $30-60 \mathrm{~s}$ at $1000 \mathrm{~g}$, drop the wash buffer and mount the bottom cap. Open the top cap of the spin column and added $100 \mu \mathrm{l}$ rehydrated elution reagent, mount the top cap, shock slightly for $5 \mathrm{~s}$ and incubated at $26^{\circ} \mathrm{C}$ for $15 \mathrm{~min}$, open the bottom cap and transfer spin column to the clean centrifuge tube, centrifuge $60 \mathrm{~s}$ at $1000 \mathrm{~g}$, label the collect fluid respectively and mount the bottom cap, add DTT to the final concentration of $10 \mathrm{mM}$ and incubated at $56^{\circ} \mathrm{C}$ for $1 \mathrm{~h}$, as the temperature retured to RT add the IAM to the final concentration of $55 \mathrm{mM}$, then added 5 times volume cold acetone, precipitate at $-20^{\circ} \mathrm{C}$ for $2 \mathrm{~h}$ then centrifuged at $30000 \mathrm{~g}, 4^{\circ} \mathrm{C}$ for $15 \mathrm{~min}$, drop the supernatant and dry the precipitate, added $200 \mu \mathrm{l}$ lysis buffer 3, ice-bath for $5 \mathrm{~min}$ and centrifuged for $15 \mathrm{~min}$ at $25000 \mathrm{~g}, 4^{\circ} \mathrm{C}$, to obtain the protein supernatant.

\section{Protein extraction and quality control}

The protein concentration was quantified using BCA kit, and the integrity of the samples were evaluated using SDS-PAGE method.

\section{Protein enzymolysis and peptide fragment labeling}

$100 \mu \mathrm{g}$ protein of each sample were taken out and hydrolyzed at $37^{\circ} \mathrm{C}$ for $4 \mathrm{~h}$, with the ratio to enzyme of trypsin as 40:1, then Strata X column was used to desalt the hydrolyzed peptide fragment. Certain iTRAQ labeling reagents were taken out and added $50 \mu \mathrm{l}$ isopropanol to each of the tube, then 0.5 M TEAB was used to dissolve the peptide fragment, and added into the corresponding labeling reagent, each different peptide fragments were labeled with specific ITRAQ tag, incubated at RT for $2 \mathrm{~h}$.

Peptide fragment separation and determined by liquid chromatography-mass spectrometry

Using liquid chromatography (LC-20AB Daojin Japan) and C18 column ( $5 \mu \mathrm{m} 4.6 \times 250 \mathrm{~mm}$ Gemini) to separate the samples, $2 \mathrm{ml}$ mobile phase A (5\% ACN pH 9.8) was used to redissolve the dried samples and injected, and the column was gradiently eluted with the speed of $1 \mathrm{ml} / \mathrm{min}$, the fraction was collected every minute under the monitoring wavelength of $214 \mathrm{~nm}, 20$ fractions were obtained in total and freeze dried, then the dried samples were redissolved with mobile phase A $(2 \% \mathrm{ACN} 0.1 \% \mathrm{FA})$, centrifuged 
at $20000 \mathrm{~g}$ for $10 \mathrm{~min}$ and collected the supernate to inject into the liquid chromatography. The samples first enriched and desalted in the trap column, then connected with self-assembly C18 column (75 $\mu \mathrm{m}$ inner diameter, $3.6 \mu \mathrm{m}$ column stuff particle size, $15 \mathrm{~cm}$ column length), separated with the flow rate of $300 \mathrm{nl} / \mathrm{min}$, and the tail end was directly connected with mass spectrometer tripleTOF 5600 (SCIEX, Framingham, MA, USA), the ion source was Nanospray III source and the radiator was the needle made from quartz material. The parameter of mass spectrometer was set as: $2300 \mathrm{~V}$ Ion source spray voltage, the nitrogen pressure was $30 \mathrm{psi}$, the atomizer was 15 , the temperature of the spray joint was $150{ }^{\circ} \mathrm{C}$, scan as the high sensitive mode, the cumulative time of first level mass spectrum was $250 \mathrm{~ms}$, the mass range of scan was 350-1500 Da, based on the first level scanning information, ranking based on the ion strength of the first level spectrogram from high to low, selecting the ion strength which exceeded 150 cp to be fragmentized and scan the secondary data, the cumulative time of second level mass spectrum was 100 ms. Data collection was based on the type of ITRAQ, and the fracture energy was adjusted based on the ITRAQ reagents, the ion transfer efficiency of second quadrupole Q2 at $100 \mathrm{Da}$ was $100 \%$.

\section{The process of proteomic information analysis}

As the original data was collected, the proteomic information analysis was conducted as described in Fig. 1, based on the analysis, the total amount of differential proteins was counted and the annotation of differential proteins between each period were conducted.

\section{RESULTS}

\section{Overview of the identified protein amounts}

In the study, we have total groups of four, be named as empty pregnant, oestrum, gestation and lactation respectively, to divide the whole reproductive cycle of black goats into these four periods. Each group had three repetitions. Finally, we generated 1011548 secondary spectrum diagram, and under the filter criteria of $1 \%$ FDR, we have identified 5745 items of peptide fragments, 5465 items of unique peptide fragments and 1213 items of proteins (Table 1). Fig. 2 showed identified protein results between replicates, it showed that 442 common protein items were found from three replicated tests, from this figure we could also calculated the common identified protein items between each replication. It could be concluded from Fig. 3 that the most abundantly distributed protein mass was above $100 \mathrm{kDa}$, and the centrally distributed protein mass scope were $10-60 \mathrm{kDa}$. From Fig. 4, we could find that the most abundantly distribute peptide length scope identified (calculated as the amount of amino acids) were 7-17 amino acids.

\section{Protein quantification based on ITRAQ technology}

In this study, we set up six comparison groups: lactation/ gestation, lactation/oestrum, estation/oestrum, empty pregnant/oestrum, empty pregnant/lactation, empty pregnant/gestation, the significant difference was screened by the criterion of Fold change $>1.2$ or $<0.83$ and $Q$ value $<0.05$, for the data of multiple tests, the final significantly different protein should be defined as significant protein at least one time ( $>$ one time). From table 2, the most differential protein amounts in total was the comparison group of empty pregnant/gestation (include both up and down regulated), 201 proteins were significantly regulated between these two periods. The amounts of significantly different proteins of continuous period comparison between empty pregnant/oestrum, gestation/oestrum and lactation/gestation were 141,170 and 159 respectively, which showed the intrinsic difference between continuous period, corresponding to Fig. 5, from the distribution diagram of CV between repetitions (Fig. 6), we could conclude that the comparison values between two periods were credible.

\section{GO and COG enrichment of differential expressed proteins during the reproduction cycle}

From Fig. 7 it could be concluded that between each two periods, in the category of biological process, the most amounts of proteins enriched were in catalytic activity and binding items, in the category of cellular component, the most amounts of proteins enriched were in cell part and cell items, and in the category of molecular function, the most amounts of proteins enriched were in single-organism process and cellular process items. From the enrichment in COG categories (Fig. 8), it could be concluded that the items of translational modification, protein turnover, chaperones and general function prediction were the most concentrated area.

KEGG enrichment of differential expressed proteins between each two periods

Two key information should be focus on in Fig. 9, protein numbers and rich factor. From Fig. 9A, it could be

Table 1: Overview of the result of protein identification.

\begin{tabular}{lcccccc}
\hline Sample name & Total spectra & Spectra & Unique spectra & Peptide & Unique peptide & Protein \\
\hline Black goats (repetition1) & 338816 & 22654 & 20776 & 3831 & 3563 & 722 \\
Black goats (repetition2) & 335614 & 23580 & 21762 & 3984 & 3760 \\
Black goats (repetition3) & 337118 & 27958 & 24944 & 4316 & 746 \\
Total & 1011548 & 74192 & 67482 & 5745 & 8983 \\
\hline
\end{tabular}




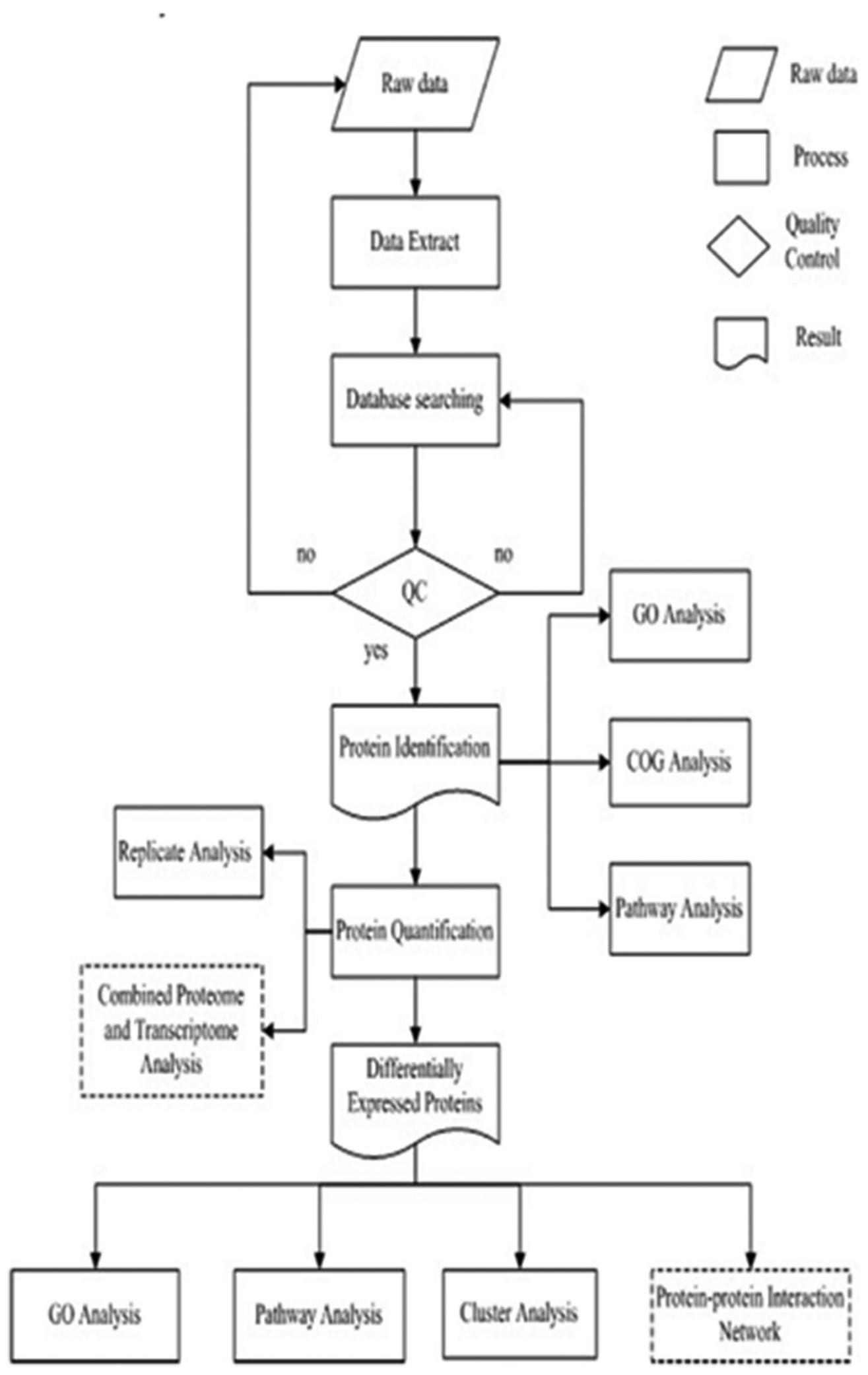

Fig 1. Bioinformatics analysis pipeline. The mass spectrometric data was converted into the formatted file type of mgf, and the protein identification software Mascot was used to search and identify the protein species based on the corresponding database. Quality analysis was also conducted to judge whether the data was qualified. As the data was credible, then certain screening threshold was set to obtain the final receivable protein data. Next quantitative analysis based on iTRAQ was conducted and concerned proteins which showed significant difference were screened out. Finally function annotation of GO, Pathway, COG of proteins and enrichment analysis of GO and Pathway of differential proteins were conducted. 
Table 2: Protein amounts list with significant difference between each period

\begin{tabular}{lccc}
\hline Compare group & $\begin{array}{c}\text { Up } \\
\text { regulated }\end{array}$ & $\begin{array}{c}\text { Down } \\
\text { regulated }\end{array}$ & $\begin{array}{c}\text { All } \\
\text { regulated }\end{array}$ \\
\hline Lactation/gestation & 58 & 101 & 159 \\
Lactation/oestrum & 93 & 79 & 172 \\
Gestation/oestrum & 101 & 69 & 170 \\
Empty pregnant/oestrum & 66 & 75 & 141 \\
Empty pregnant/lactation & 46 & 60 & 106 \\
Empty pregnant/gestation & 63 & 138 & 201 \\
\hline
\end{tabular}

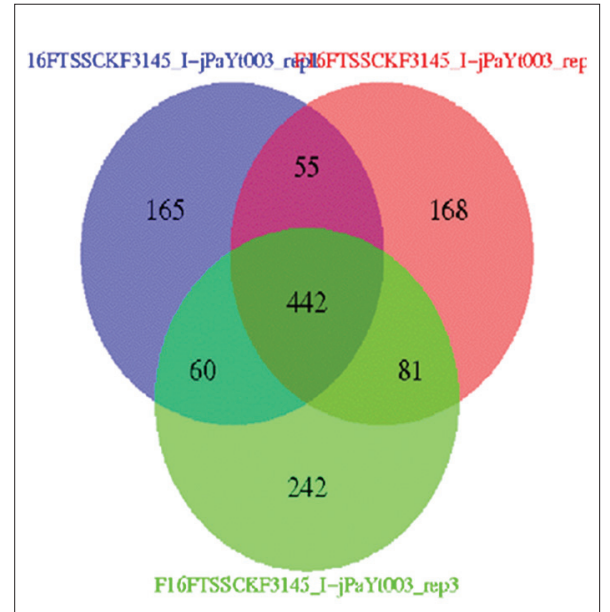

Fig 2. Venn diagram of protein identification. Venn diagram describing identified protein results between replicates. The blue, red and green color represented replication 1, 2, 3 respectively, and the common part between each replication represented intersection protein items. concluded that the dot of the highest protein numbers and the most significant rich factor were inconsistent, the pathway related to complement and coagulation cascades, and p53 signaling pathway respectively, as to Fig. 9B, the highest protein numbers and the most significant rich factor were complement and coagulation cascades, prolaction signaling pathway respectively, as to Fig. 9C, the rule was the same with Fig. 9A, Fig. 9D showed the same rule with Fig. 9A in the area of highest protein numbers, but the most significant rich factor located on fanconi anemia pathway, as to Fig. 9E, the highest protein numbers and the most significant rich factor were metabolic pathways and arachidonic acid metabolism, Fig. 9F showed the complement and coagulation cascades and adipocytokine signaling pathway as the highest protein numbers and the most significant rich factor respectively.

\section{Continuously differential expression proteins of the whole cycle}

As seen in table 3, there are total five proteins which showed significantly differential expression between the adjacent stages: C4b-binding protein alpha chain isoform X4 (C4BP $\propto$ X4), coagulation factor IX (FIX), leukocyte cell-derived chemotaxin-2 (LECT2), hyaluronan-binding protein 2 isoform X2 (HABP 2 X2) and Apolipoprotein C-II isoform X2 (ApoC-II X2) respectively. The level of C4BP $\alpha$ X4 showed downregulated rule from empty pregnant to gestation, and then increased in the period of lactation, the level of

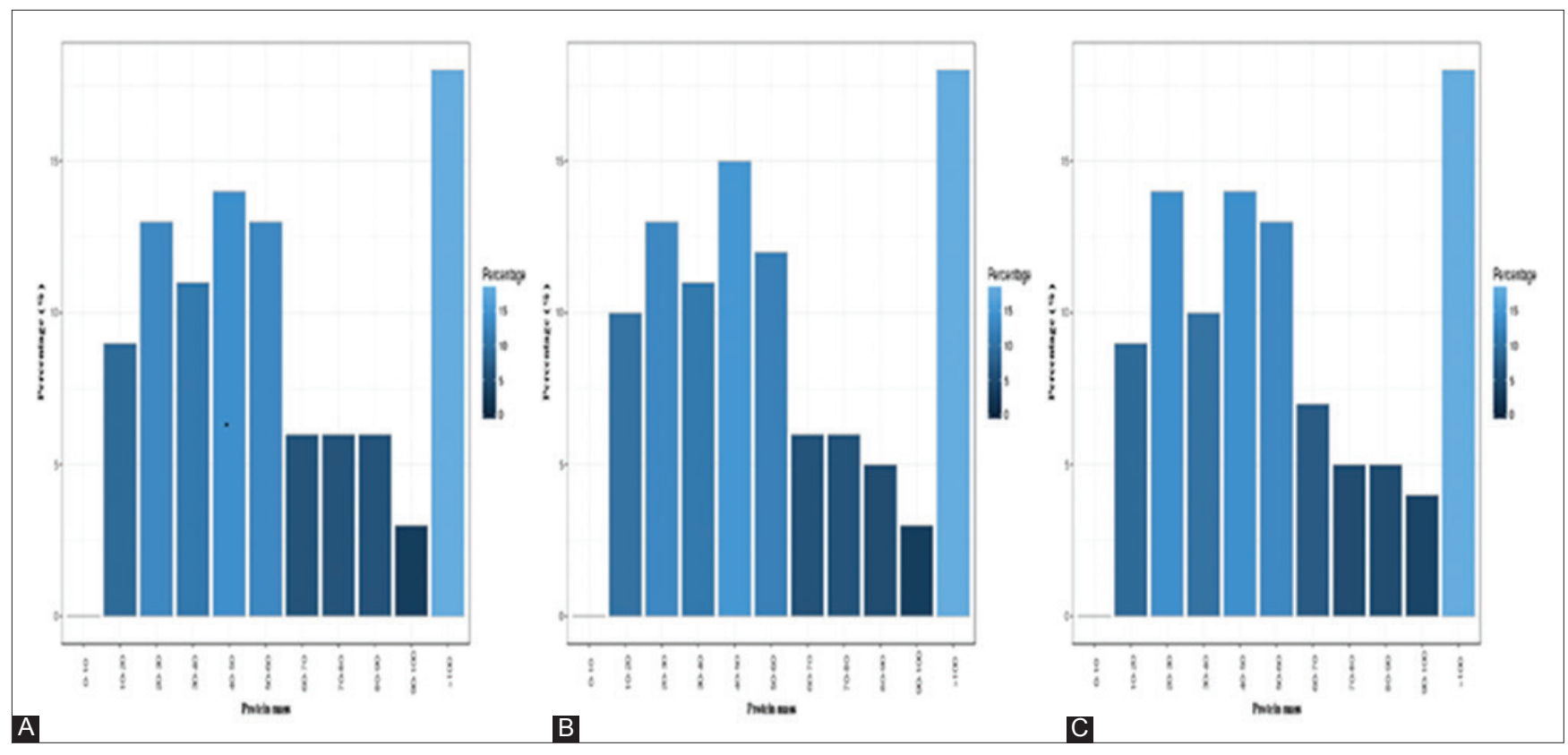

Fig 3. Distribution map of protein molecular weight. The map showed the distribution status of protein molecular weight of the whole identified items. (A) The total protein molecular weight distribution level in replication 1, (B) The total protein molecular weight distribution level in replication 2 , (C) The total protein molecular weight distribution level in replication 3. X-axis: The scope of protein molecular weight (kDa), Y-axis: The ratio of corresponding proteins. 


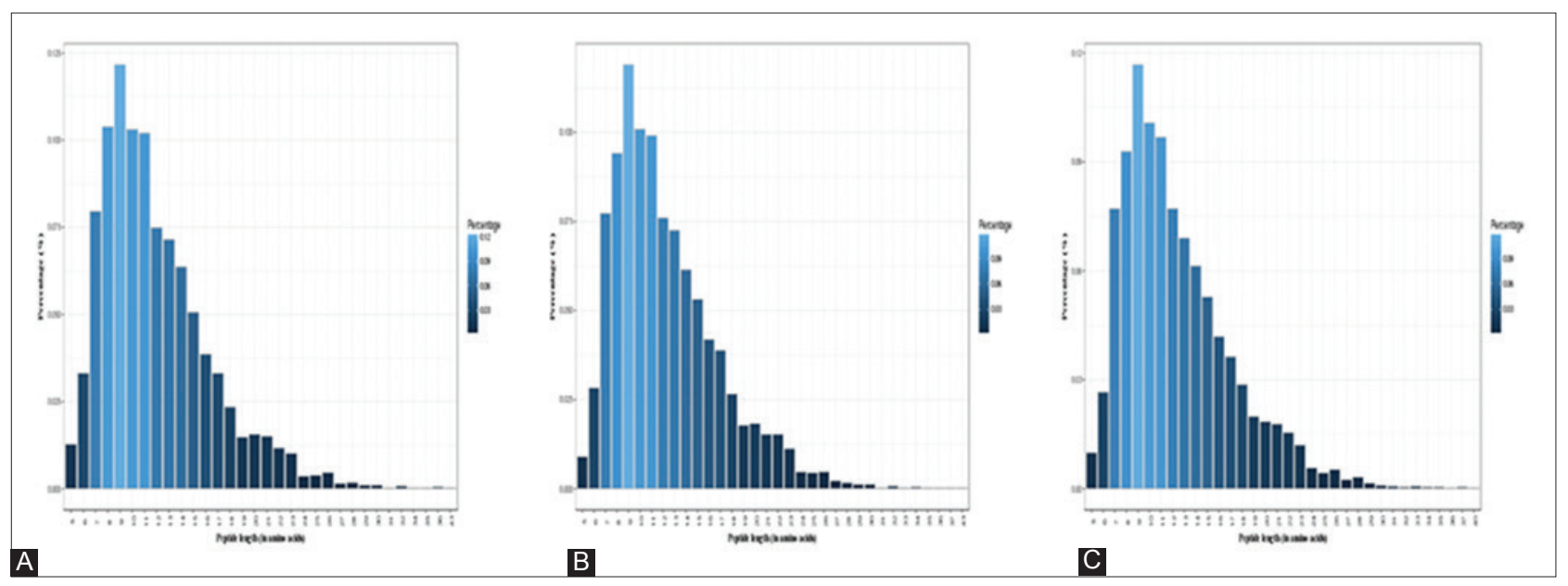

Fig 4. Distribution map of peptides length. This map showed the distribution status of peptide length of the whole identified peptide fragments. (A) The total peptides length distribution level in replication 1, (B) The total peptides length distribution level in replication 2, (C) The total peptides length distribution level in replication 3. X-axis: The length of peptide fragments (calculated as the amount of amino acids), Y-axis: The ratio of corresponding peptide fragments.

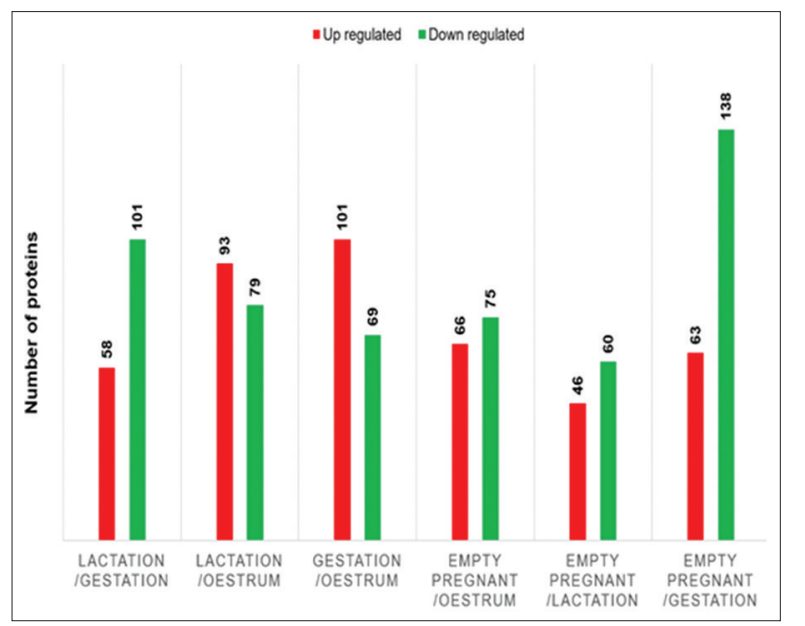

Fig 5. Bar graph of significantly different proteins. X-axis: The information of compared groups, Y-axis: The amounts of significantly different proteins. The bar with green color means significantly down regulated proteins, the bar with red color means significantly up regulated proteins.

FIX showed down regulated from empty pregnant to oestrum, and then increased in the period of gestation, finally reduced in the lactation period, the level of LECT2, HABP 2 X2 and apoC-II X2 showed the same changing tendency with FIX.

\section{Differential expression proteins directly related to reproduction between two adjacent period}

As listed in table 4, There are total eight proteins showed differential expression between two adjacent periods which directly related to reproduction, that are serum amyloid A21 precursor (SAA21), anthrax toxin receptor 2 (ANTXR2), von Willebrand factor (VWF), secreted frizzled-related protein 3 (Sfrp 3), Beta-1,4-galactosyltransferase 1 (Beta1,4-GalT 1), insulin-like growth factor-binding protein
Table 3: Continuously differential expression proteins of the whole cycle

\begin{tabular}{lccc}
$\begin{array}{l}\text { Protein } \\
\text { items }\end{array}$ & $\begin{array}{c}\text { Oestrum/empty } \\
\text { pregnant }\end{array}$ & $\begin{array}{c}\text { Gestation/ } \\
\text { oestation }\end{array}$ & $\begin{array}{c}\text { Lactation/ } \\
\text { geatation }\end{array}$ \\
\hline C4BP $\alpha$ X4 & $\downarrow 0.74$ & $\downarrow 0.77$ & $\uparrow 1.41$ \\
FIX & $\downarrow 0.71$ & $\uparrow 1.88$ & $\downarrow 0.87$ \\
LECT2 & $\downarrow 0.74$ & $\uparrow 1.59$ & $\downarrow 0.74$ \\
HABP2X2 & $\downarrow 0.8$ & $\uparrow 2.75$ & $\downarrow 0.36$ \\
ApoC-IIX2 & $\downarrow 0.78$ & $\uparrow 1.29$ & $\downarrow 0.6$ \\
\hline
\end{tabular}

Table 4: Differential expression proteins directly related to reproduction between two adjacent period

\begin{tabular}{lccc}
\hline Protein items & $\begin{array}{c}\text { Oestrum/empty } \\
\text { pregnant }\end{array}$ & $\begin{array}{c}\text { Gestation/ } \\
\text { oestation }\end{array}$ & $\begin{array}{c}\text { Lactation/ } \\
\text { gestation }\end{array}$ \\
\hline SAA21 & - & $\uparrow 1.76$ & - \\
ANTXR2 & $\downarrow 0.72$ & $\downarrow 0.65$ & - \\
VWF & - & $\downarrow 0.74$ & $\uparrow 1.28$ \\
Sfrp 3 & $\downarrow 0.72$ & $\downarrow 0.61$ & $\downarrow 0.36$ \\
Beta-1,4-GalT 1 & $\downarrow 0.56$ & - & $\downarrow 0.52$ \\
IGFBP-rP2 & - & $\uparrow 1.99$ & $\uparrow 0.65$ \\
GTP-binding & - & $\downarrow 0.48$ & - \\
protein & & & - \\
RBP4 & $\downarrow 0.70$ & - & - \\
\hline
\end{tabular}

“-” means no significant difference between two adjacent period.

2 precursor (IGFBP-rP2), GTP-binding nuclear protein Ran (GTP-binding protein), retinol-binding protein 4 precursor (RBP4). The ratio of oestrum/empty pregnant showed down-regulated in ANTXR2, Sfrp 3, beta-1,4-GalT 1 and RBP4, and the ratio of gestation/oestrum showed up-regulated in SAA21 and IGFBP-rP2 and showed down-regulated in ANTXR2, VWF, Sfrp 3 and GTPbinding protein, the ratio of lactation/gestation showed up-reuglated in VWF and down-regulated in beta-1,4-GalT 1 and IGFBP-rP2, the ratio of empty pregnant/lactation showed up-regulated in GTP-binding protein and downregulated in IGFBP-rP2. 


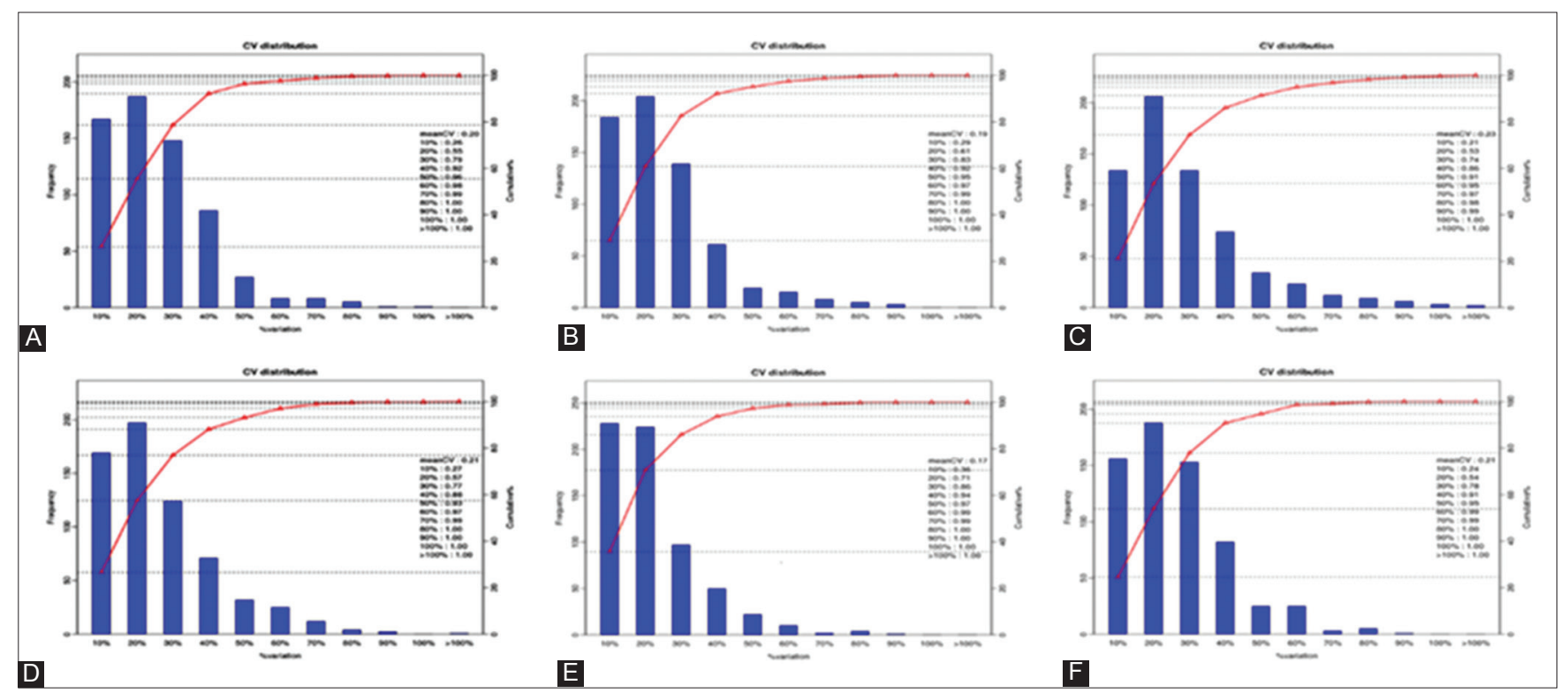

Fig 6. Distribution diagram of coefficient of variation (CV) of repetitions. (A) CV value distribution of Lactation/gestation, (B) CV value distribution of lactation/oestrum, (C) CV value distribution of gestation/oestrum, (D) CV value distribution of empty pregnant/oestrum, (E) CV value distribution of empty pregnant/lactation, (F) CV value distribution of empty pregnant/gestation. X-axis: Distribution range of CV, 10\% means $0-10 \%, 20 \%$ means $10 \%$ to $20 \%$, by parity of reasoning, Y-axis: The amounts of proteins within corresponding CV range. Right side of the chart was the accumulation ratio of proteins of each $\mathrm{CV}$ range.

\section{DISCUSSION}

The goat populations in China was the most abundant around the world (Wang et al., 2015a; Wu et al., 2009), Hainan black goat was the specific species in China, Hainan province. The meat-type goat breed has the excellent characteristics of heat resistance (Wang et al., 2014a), in recent years, with the increase in farm size and the number of goats bred, the low farrowing rate and milkability have exerted increasing influence on the scale of Hainan black goat. There were a few reports on the genetic diversity (Zhou et al., 2012), inflammasome components (Zhang et al., 2017) and nutrition regulation methods (Wang et al., 2014b; Wang et al., 2017; Wang et al., 2015b) of Hainan black goat, however, so far, there still no report on the reproductive law of this specific goat species, the study was the first research on the reproduction characteristics of Hainan black goat, we aimed to improve the fertility of this species through uncovering the internal rule of the changing of serum proteins during the whole reproductive cycle.

There were five proteins showed continuously differential expression between two adjacent stages during the whole reproductive cycle, that were C4b-binding protein alpha chain isoform X4, coagulation factor IX, leukocyte cell-derived chemotaxin-2, hyaluronan-binding protein 2 isoform X2 and apolipoprotein C-II isoform X2 respectively. And eight proteins in total directly corrected with reproduction showed significantly differential expression between two adjacent stages, that were serum amyloid A21 precursor, anthrax toxin receptor 2, von Willebrand factor, secreted frizzled-related protein 3, beta-1,4-galactosyltransferase 1, insulin-like growth factorbinding protein 2 precursor, GTP-binding nuclear protein Ran and retinol-binding protein 4 precursor.

We first focused on the five continuously differential expression proteins, based on the go analysis, the role of C4b-binding protein were Innate immune response and complement activation, it has reported that C4BP could inhibit TLR2 and TLR4 induced proinflammatory reaction through interacting with them (Morita et al., 2017), from the study of human serum C4BP, it showed that C4BP could inhibit islet amyloid polypeptide-mediated inflammasome activation and IL-1 $\beta$ production (Kulak et al., 2017), we found that compared with empty pregnant period, the level of serum C4BP in gestation reduced to the ratio of 0.74 , and the level was further down-regulated to the ratio of 0.77 compared with oestrum, and then up-regulated to the ratio of 1.41 compared with gestation group, it indicated that during the period of oestrum and gestation, the Hainan black sheep are more sensitive to inflammatory stimulation, and more preventive methods of anti-inflammation should be adopted.

Coagulation factor IX (FIX) is an essential plasma protein for blood coagulation (Ishikawa et al., 2016) and the protein seemed closely related with hemophilia (Tortella et al., 2018, Santagostino, 2016), but recently it also reported that the 


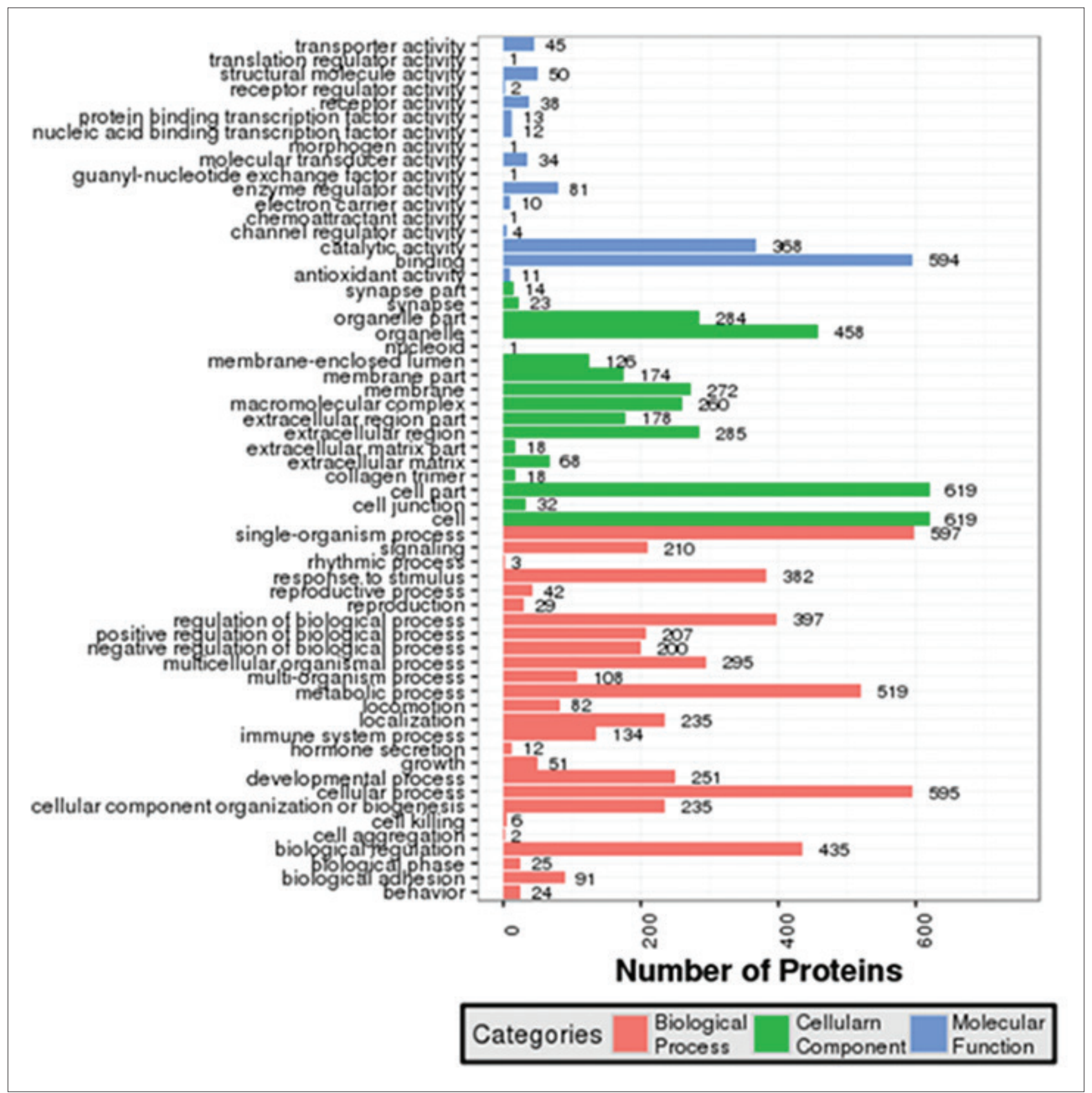

Fig 7. Histogram of GO annotation. The histogram showed GO annotation of three classification. Blue represented the molecular function, green represented the cellular component and red represented the kind of biological process.

effects of FIX on enhancing cell matrix and intercellular adhesion (Mamiya et al., 2016). The ratio of FIX in oestrum down-regulated to 0.71 compared with empty pregnant, and up-regulated to the ratio of 1.88 compared between gestation and oestrum, finally reduced to the ratio of 0.87 compared between lactation and gestation, it indicated that in the period of oestrum and lactation, more hormones and nutrition nutrient needed to pass through the endothelial cells, so lower level of FIX may increase the permeability of endothelial layer and in favour of the transport efficiency of different kinds of small functional molecules, and in the period of gestation, for the protection of the fetus in uterus, the up-regulated level of FIX mean the small molecules become more difficult to penetrate through the endothelial layer, to avoid hazardous substance and pathogenic bacteria as much as possible.

The protein of Leukocyte Cell-derived Chemotaxin 2 (LECT2) seemed to be more correlated with atherosclerosis (Sonmez et al., 2016), it was also reported that LECT2 is associated with the severity of systemic inflammation in patients with sepsis (Ando et al., 2012) and it involved in the regulation of the homeostasis of natural killer T-cell in mammals (Xu et al., 2014), in the 


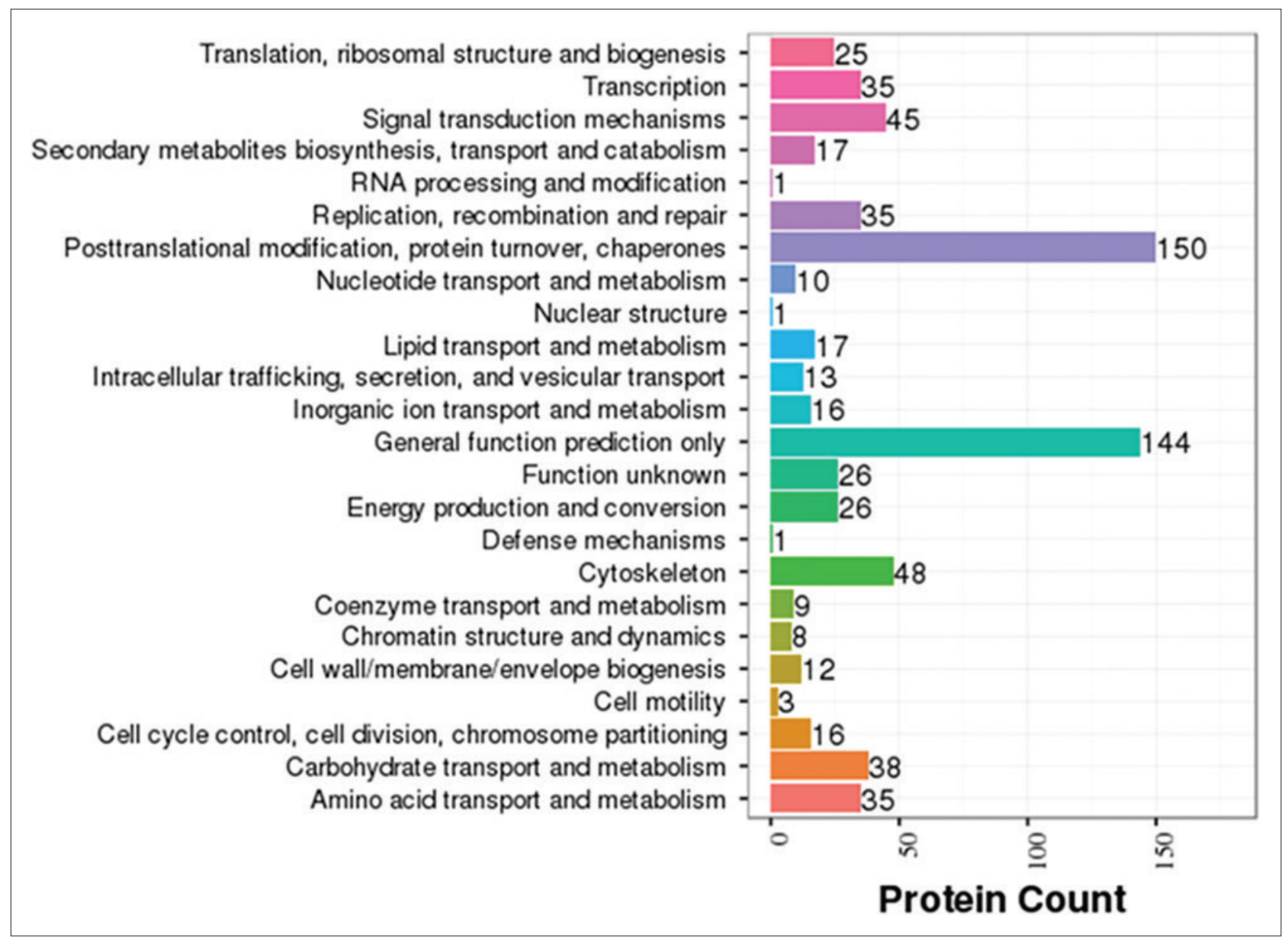

Fig 8. Histogram of COG annotation. X-axis: The protein amounts been classified into corresponding COG annotation, Y-axis: Items of COG.

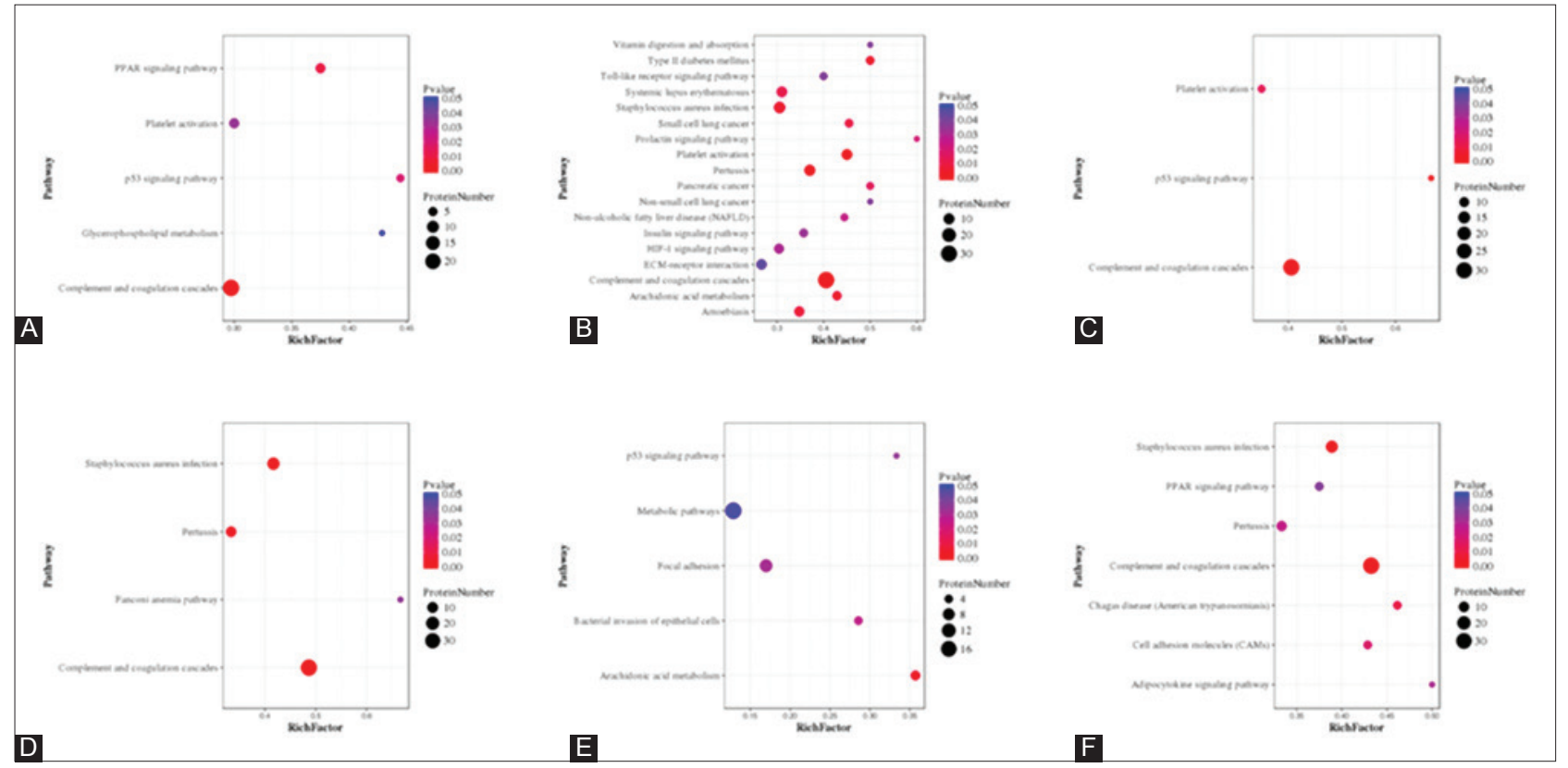

Fig 9. Statistical graph of significantly enriched pathway. (A) Enriched pathway distribution of lactation/gestation, (B) Enriched pathway distribution of lactation/oestrum, (C) Enriched pathway distribution of gestation/oestrum, (D) Enriched pathway distribution of empty pregnant/oestrum, (E) Enriched pathway distribution of empty pregnant/lactation, (F) Enriched pathway distribution of empty pregnant/gestation. X-axis: Rich factor showed the ratio of items of differential expression proteins in the specific pathway to all the identified proteins annotated in the corresponding pathway, the larger of this value, the greater ratio of differential expression proteins annotated in the corresponding pathway. Y-axis: Certain pathway items. The size of the dot means the amount of differential expression proteins annotated in certain pathway. 
period of oesturm and lactation, the level of LECT2 was down-regulated, it indicated that the Hainan black sheep were more sensitive to pathogenic bacteria and virus challenge during this two period, on the contrary, in the period of empty pregnant and gestation, the disease resistant ability was relatively high. Based on $\mathrm{GO}$ analysis, the main function of hyaluronan-binding protein is proteolysis.

It is reported that HABP 2 is a $\mathrm{Ca} 2+$ dependent serine protease with putative roles in blood coagulation and fibrinolysis (Stavenuiter et al., 2017), and hyaluronan degradation is accelerated in inflammatory and neoplastic diseases (Yoshida et al., 2013), HABP also involved in Hyaluronan depolymerization and its metabolism (Shimoda et al., 2017), The ratio of HABP 2 in oestrum reduced to 0.8 compared with empty pregnant, and up-regulated to the ratio of 2.75 compared between gestation and oestrum, compared with gestation, the level of HABP 2 protein up-regulated to the ratio of 0.36 in lactation, it indicated that in the period of gestation and empty pregnant, the inflammatory status are high, and the inflammatory status in the period of oestrum and lactation are low, and anti-inflammatory steps should be taken in the period of gestation and empty pregnant.

Apolipoprotein C -II (apoC-II) is an important co-factor for lipoprotein lipase (Kei et al., 2012), and based on GO analysis, the function of apo C-II were related to positive regulation of triglyceride catabolic process, phospholipid catabolic process and lipoprotein lipase activity. As apoC-II is a small exchangeable apolipoprote on triglyceride-rich lipoproteins (Wolska et al., 2017), it could hydrolyze triacylglycerol and reduce the corresponding concentration in serum. The ratio of apoC-II in oestrum reduced to 0.78 compared with empty pregnant, and up-regulated to the ratio of 1.29 compared between gestation and oestrum, compared with gestation, the level of apoC-II protein up-regulated to the ratio of 0.6 in lactation, the data showed the concentration of triacylglycerol in serum of empty pregnant and gestation were relatively higher than the period of oestrum and lactation, which indicated that during the period of empty pregnant and gestation, lower energy level diets could be supplied and correspondingly higher energy level diets should be provided in the period of oestrum and lactation.

\section{CONCLUSION}

This is the first study systematically uncovered reproductive cycle characteristics of Hainan black goats, the study preliminarily uncovered the basical protein information between each reproductive period, and the data could contribute to the built of highly efficient reproduction system of Hainan black goats.

\section{ACKNOWLEDGMENTS}

This study was financially supported by the key technology research and integration application of large-scale healthy breeding of Hainan black goats (Grant No. ZDKJ2016017) and Research and application of meat key gene screening and molecular assistant breeding of the special wild boar in Hainan Province (Grant No. ZDYF2017059).

\section{REFERENCES}

Adamala, S. 2018. Temperature based generalized wavelet-neural network models to estimate evapotranspiration in India. Inform. Process. Agric. 5(1): 149-155.

Al-zaqri, N., A. Alsalme, S.F. Adil A. Alsaleh, S.G. Alshammari, S.I. Alresayes, R. Alotaibi, M. Al-Kinany and M.R.H. Siddiqui. 2017. Comparative catalytic evaluation of nickel and cobalt substituted phosphomolybdic acid catalyst supported on silica for hydrodesulfurization of thiophene. J. Saudi Chem. Soc. 21(8): 965-973.

Ando, K., H. Kato, T. Kotani, M. Ozaki, Y. Arimura and J. Yagi. 2012. Plasma leukocyte cell-derived chemotaxin 2 is associated with the severity of systemic inflammation in patients with sepsis. Microbiol. Immunol. 56: 708-718.

Basak, B.B and N.A. Gajbhiye. 2018. Herbage yield and bioactive principle of senna as influenced by micronutrient application in soil. J. Environ. Biol. 39(1): 43-49.

Basu, A., J. Schell and R.H. Scofield. 2018. Dietary fruits and arthritis. Food Funct. 9(1): 70-77.

Camara, E.M., E.P. Caramaschi, F. Di Dario and A.C. Petry. 2018. Short-term changes in two tropical coastal lagoons: Effects of sandbar openings on fish assemblages. J. Coast. Res. 34(1): 90-105.

Chiaradia, E., L. Avellini, M. Tartaglia, A. Gaiti, I. Just, F. Scoppetta, Z. Czentnar and A. Pich. 2012. Proteomic evaluation of sheep serum proteins. BMC Vet. Res. 8: 66.

Duan, M., Z. Liu, D. Yan, W. Peng and A. Baghban. 2018. Application of Issvm algorithm for estimating higher heating value of biomass based on ultimate analysis. Rec. Util. Environ. Eff. 40(6): 709-715.

Fu, $\mathrm{H}$ and X. Liu. 2017. A study on the impact of environmental education on individuals' behaviors concerning recycled water reuse. Eurasia J. Math. Sci. Technol. Educ. 13(10): 6715-6724.

Garcia Alegria, A.M., A. Gomez-Alvarez, I. Anduro-Corona, A. BurgosHernandez, E. Ruiz-Bustos, R. Canett-Romero and H. Francisco Astiazaran-Garcia. 2017. Optimization of the ideal analytical conditions for quantifying aluminum in sprague dawley rats using the atomic absorption technique. Rev. Int. Contaminacion Ambient. 33(SI): 77-84.

Gonzalez-Trinidad, J., H.E. Junez-Ferreira, A. Pacheco-Guerrero, E. Olmos-Trujillo and C.F. Bautista-Capetillo. 2017. Dynamics of land cover changes and delineation of groundwater recharge potential sites in the aguanaval aquifer, zacatecas, Mexico. Appl. Ecol. Environ. Res. 15(3): 387-402.

Hasan, M.M. 2018. Bioaugmentation approach in rhizospheric microbiome research: A lesson from arsenic remediation. 
Malays. J. Halal Res. 1(1): 15-16.

Howlader, M.H.K., M.N. Islam, S. Biswas, M.E. Uddin, A. Shila M. Haque and N. Mahmud. 2018. Salt tolerance of chili genotypes during germination and seedling growth. Malays. J. Halal Res. 1(2): $1-7$.

Ishikawa, T., H. Kitano, A. Mamiya, S. Kokubun and C. Hidai. 2016. The first Egf domain of coagulation factor ix attenuates cell adhesion and induces apoptosis. Biosci. Rep. 36: 12-17.

Jiao, J., S. Wang, R. Zhang, Z. Ma, G. Du, X. Chen, D. Tao and J. Zhao. 2017. Itraq-based quantitative proteomics discovering potential serum biomarkers in locoweed poisoned rabbits. Chem. Biol. Interact. 268: 111-118.

Kannan, P., P. Jithinraj and M. Natesan. 2018. Multiphasic inhibition of mild steel corrosion in h2s gas environment. Arabian J. Chem. 11(3): 388-404.

Kei, A.A., T.D. Filippatos, V. Tsimihodimos and M.S. Elisaf. 2012. A review of the role of apolipoprotein C-li in lipoprotein metabolism and cardiovascular disease. Metabolism. 61: 906-921.

Khan. M.M. 2018. Occurrence, distribution, host preference and damage severity of red pumpkin beetle - A review. Malays. J. Halal Res. J. 1(1): 3-9.

Koutroukides, T.A., J.A. Jaros, B. Amess, D. Martins-De-Souza, P.C. Guest, H. Rahmoune, Y. Levin, M. Deery, P. D. Charles, S. Hester, A. Groen, A. Christoforou, J. Howard, N. Bond, S. Bahn and K.S. Lilley. 2013. Identification of protein biomarkers in human serum using itraq and shotgun mass spectrometry. Methods Mol. Biol. 1061: 291-307.

Kulak, K., G.T. Westermark, N. Papac-Milicevic, E. Renstrom, A.M. Blom and B.C. King. 2017. The human serum protein C4bbinding protein inhibits pancreatic iapp-induced inflammasome activation. Diabetologia. 60: 1522-1533.

Kylili, A., P.A. Fokaides, A. Ioannides and S. Kalogirou. 2018. Environmental assessment of solar thermal systems for the industrial sector. J. Clean. Prod. 176: 99-109.

Li, G., C. Sun, G. Wu, F. Shi, A. Liu and N. Yang. 2016. Itraq-based quantitative proteomics identifies potential regulatory proteins involved in chicken eggshell brownness. PLoS One. 11: E0168750.

Li, Y., G. Zhou, R. Zhang, J. Guo, C. Li, G. Martin, Y. Chen and X. Wang. 2018. Comparative proteomic analyses using itraqlabeling provides insights into fiber diversity in sheep and goats. J. Proteomics. 172: 82-88.

Maddi, B., S. Viamajala and S. Varanasi. 2018. Pyrolytic fractionation: A promising thermochemical technique for processing oleaginous (algal) biomass. Acs Sustain. Chem. Eng. 6(1): 237-247.

Mamiya, A., H. Kitano, S. Kokubun and S. Hidai. 2016. Activation peptide of coagulation factor Ix regulates endothelial permeability. Transl. Res. 177: 70-84.

Morita, N., T. Yamazaki, Y. Murakami, R. Fukui, I. Yamai, I. Ichimonji, A. Nakashima, F. Nagaoka, H. Takagi, K. Miyake and S. Akashi-Takamura, 2017. C4b-binding protein negatively regulates TIr4/Md-2 response but not TIr3 response. Febs. Lett. 591: 1732-1741.

Moulder, R., S.D. Bhosale, D.R. Goodlett and R. Lahesmaa. 2017. Analysis of the plasma proteome using itraq and tmt-based isobaric labeling. Mass Spectrom. Rev. 37(5):583-606.

Qu, C., D. Wen-Bin and G. Yun. 2017. Russia forest resource management. Malays. J. Sustain. Agric. 1(2): 12-14.

Ren, W., X. Hou, Y. Wang, W. Badgery, X. Li, Y. Ding, H. Guo, Z. Wu, N. Hu, L. Kong, C. Chang, C. Jiang and J. Zhang. 2016. Overgrazing induces alterations in the hepatic proteome of sheep (Ovis Aries): An itraq-based quantitative proteomic analysis. Proteome Sci. 15: 2.

Santagostino, E. 2016. Transforming the treatment for hemophilia B patients: Update on the clinical development of recombinant fusion protein linking recombinant coagulation factor IX with recombinant albumin (Rix-Fp). Thromb. Res. 141(3): 5-8.

Shimoda, M., H. Yoshida, S. Mizuno, T. Hirozane, K. Horiuchi, Y. Yoshino, H. Hara, Y. Kanai, S. Inoue, M. Ishijima and Y. Okada. 2017. Hyaluronan-binding protein involved in hyaluronan depolymerization controls endochondral ossification through hyaluronan metabolism. Am. J. Pathol. 187: 1162-1176.

Sonmez, F.C., P. Yildiz, M.S. Akhtar, C. Aydin, C. Sonmez, N. Ay and M.A. Vatankulu. 2016. New markers in atherosclerosis: Thrombospondin-2 (Thbs-2) and leukocyte cell-derived chemotaxin-2 (Lect-2); an immunohistochemical study. Med. Sci. Monit. 22: 5234-5239.

Stavenuiter, F., E. Ebberink, K. Mertens and A.B. Meijer. 2017. Role of glycine 221 in catalytic activity of hyaluronan-binding protein 2. J. Biol. Chem. 292: 6381-6388.

Tonack, S., M. Aspinall-O'dea, R.E. Jenkins, V. Elliot, S. Murray, C.S. Lane, N.R. Kitteringham, J.P. Neoptolemos and E. Costello. 2009. A technically detailed and pragmatic protocol for quantitative serum proteomics using itraq. J. Proteomics. 73: 352-6.

Tortella, B.J., J. Alvir, M. Mcdonald, D. Spurden, P.F. Fogarty, A. Chhabra and A.M. Pleil. 2018. Real-world analysis of dispensed lus of coagulation factor $\mathrm{Ix}$ and resultant expenditures in hemophilia B patients receiving standard half-life versus extended half-life products and those switching from standard half-life to extended half-life products. J. Manag. Care Spec. Pharm. 12: 1-10.

Troujeni, M.E., M. Khojastehpour, A. Vahedi and B. Emadi. 2018. Sensitivity analysis of energy inputs and economic evaluation of pomegranate production in Iran. Inform. Process. Agric. 5(1):114-123.

Tu, D., Y. Chang, C. Chou, Y. Lin, C. Chiang, Y. Chang and Y. Chen. 2018. Preventive effects of taurine against d-galactose-induced cognitive dysfunction and brain damage. Food Funct. 9(1): 124-133.

Wang, D., L. Zhou, H. Zhou, G. Hou, M. Li, L. Shi, X. Huang and S. Guan. 2014a. Effects of nutrition level of concentrate-based diets on growth performance and carcass characteristics of Hainan black goats. Trop. Anim. Health Prod. 46: 783-788.

Wang, D., L. Zhou, H. Zhou, G. Hou, L. Shi M. Li X. Huang and S. Guan. 2015a. Effects of nutritional level of concentrate-based diets on meat quality and expression levels of genes related to meat quality in Hainan black goats. Anim. Sci. J. 86: 166-173.

Wang, D.F., L.L. Zhou, H.L. Zhou, G.Y. Hou M. Li, L.G. Shi, X.Z. Huang and S. Guan. 2014b. Effects of nutrition level of concentratebased diets on growth performance and carcass characteristics of Hainan black goats. Trop. Anim. Health Prod. 46: 783-788.

Wang, D.F., L.L. Zhou, H.L. Zhou, G.Y. Hou and L.G. Shi. 2017 Effects of dietary alpha-lipoic acid on carcass characteristics, antioxidant capability and meat quality in Hainan black goats. Ital. J. Anim. Sci. 16: 61-67.

Wang, D.F., L.L. Zhou, H.L. Zhou, G.Y. Hou, L.G. Shi, M. Li, X.Z. Huang and S. Guan. 2015b. Effects of nutritional level of concentrate-based diets on meat quality and expression levels of genes related to meat quality in Hainan black goats. Anim. Sci. J. 86: 166-173.

Wolska, A., R.L. Dunbar, L.A. Freeman, M. Ueda, M.J. Amar D.O. Sviridov and A.T. Remaley. 2017. Apolipoprotein C-li: New findings related to genetics, biochemistry, and role in triglyceride metabolism. Atherosclerosis. 267: 49-60. 
Wu, Y.P., W.J. Guan, Q.J. Zhao X.H. He, Y.B. Pu, J.H. Huo, J.F. Xie, J.L. Han, S.Q. Rao and Y.H. Ma. 2009. A fine map for maternal lineage analysis by mitochondrial hypervariable region in 12 Chinese goat breeds. Anim. Sci. J. 80: 372-380.

Xing, T., C. Wang, X. Zhao, C. Dai, G. Zhou and X. Xu. 2017. Proteome analysis using isobaric tags for relative and absolute analysis quantitation (Itraq) Reveals alterations in stressinduced dysfunctional chicken muscle. J. Agric. Food Chem. 65: 2913-2922.

Xu, J.W., Y.L. Li, S.J. Zhang, W.Q. Yang, W.T. Nie and H.Q. Jiang. 2017. Quantitative serum proteomic analysis of essential hypertension using itraq technique. Biomed. Res. Int. 2017: 6761549.

Xu, Q., Y. Chen, Y.Y. Tong, Z.Y. Huang, W.M. Zhao, X.J. Duan, Y. Zhang, X. Li, G.B. Chang and G.H. Chen. 2014. Identification and expression analysis of the leukocyte cell-derived chemotaxin-2, Gene in duck (Anas Platyrhynchos). Gene. 533: 280-285.

Yoshida, H., A. Nagaoka, A. Kusaka-Kikushima, M. Tobiishi K. Kawabata, T. Sayo, S. Sakai, Y. Sugiyama H. Enomoto Y. Okada and S. Inoue 2013. A deafness gene of unknown function, is a new hyaluronan binding protein involved in hyaluronan depolymerization. Proc. Natl. Acad. Sci. 110: 5612-5617.

Yun, G., S. Williams and D. Wenbin. 2017. Water management of the Mekong river. Malays. J. Sustain. Agric. 1(2):15-17.

Zhang, K.Z., P. Tao, J.X. Liu, Q.N. Wang, S.K. Ge and Z.Y. Ning. 2017. Distinct expression profile and histological distribution of nlrp3 inflammasome components in the tissues of Hainan black goat suggest a site-specific role in the inflammatory response. Acta Vet. Hung. 65: 402-416.

Zhang, X., Y. Chen, J. Pan, X. Liu, H. Chen, X. Zhou,Z. Yuan, X. Wang and D. Mo. 2016. Itraq-based quantitative proteomic analysis reveals the distinct early embryo myofiber type characteristics involved in landrace and miniature pig. BMC Genomics. 17: 137.

Zhou, H.L., S. Guan, G.Y. Hou, D.J. Wang, T.S. Xu, D.F. Wang, L.G. Shi, G. Rong and M. Li. 2012. The genetic diversity of Hainan black goat by capillary gel electrophoresis with microsatellite markers in tropical area of China. J. Anim. Vet. Adv. 11: 3378-3384.

Zong, H., Y. Cao and Z. Liu. 2018. Energy security in group of seven (g7): A quantitative approach for renewable energy policy. Energy Sour. Part B-Econ. Plan. Policy. 13(3): 173-175. 